It follows that yeast nucleic acid as well as thymonucleic acid only slow down the process of gelatina. tion, whereas adenosine-3-phosphoric acid inhibits it. With this latter substance the clotting time of fibrinogen by thrombin is twenty times as long as with yeast nucleic acid.

The adenosine-3-phosphoric acid was provided by Messrs. Hoffmann-La Roche and Co., Basle.

University Medical Clinic, Ch. WUNDERLY Zurich. Sept. 10.

' Astrup, F., and Darling, S., Acta Physiol. Scand., 4, 45 (1942). 2 Rosenfleld, R., and Tuft, H. S., Amer. J. Clin. Path., 17, 405 (1947). "Owren, P. A., "The Coagulation of Blood", 86 (Oslo, 1947). s Wunderly, Ch., Experientia, 4, 486 (1948).

\section{Action of 'Blood-Group Substances' on the Anti-Ken Serum}

Sncer the publication of our previous communication $^{1}$, we have continued our investigations with the anti-Ken serum, but after adding Witebsky's 'purified blood-group substances', supplied by the courtesy of Sharp and Dohme, Philadelphia.

Testing 248 unselected bloods with the original serum gave the following results ${ }^{1}$ :

$$
\begin{array}{lrr}
A \text { cells } & + & \overline{46} \\
0 \text { cells } & 102 & 45 \\
& & 55
\end{array}
$$

Testing 300 unselected bloods with the 'absorbed anti-Ken' serum gave a different distribution :

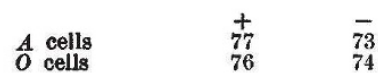

We do not find in our new series tested with the 'absorbed' serum the difference observed previously when using the original serum; but, on the contrary, there is an even ratio of about 50 per cent + and 50 per cent - reactions in both $O$ - and $A$-groups. This ratio was actually the one found in the $A$-cell group when using the original serum.

Thus the addition of 'blood-group substances' seems to inhibit the constituent of the original serum responsible for the agglutination of some 15 per cent of extra-bloods in the $O$ cell group. This indicates that the original serum contains two antibodies.

Unfortunately, our stock of the original anti-Ken had come to an end when we realized this fact. The patient was bled, but the agglutinin(s) had disappeared from her serum. We are now attempting to get an immune reaction by inoculating her with small amounts of Ken + blood.

Priority in the recognition of the phenomenon we have described should go to $R$. R. Race ${ }^{2}$, when absorbing Andresen's ${ }^{8}$ anti- $L_{2}$ with the $A$ bloodgroup substance prepared by W. T. J. Morgan. There is, indeed, a close similarity between $L_{2}$ and Ken : the positive and negative reactions of anti- $L_{2}$ and anti-Ken are distributed similarly with a differ. ence between $O$. and $A$-cell groups; on the other hand, both sera behave in the same way when in contact with 'blood-group substancos'.

Laboratoire de Bacteriologie

PibrRe O. HubINoNT

ot Laboratoire d'Hygiene,

Université Libre de Bruxelles.

$$
\text { Nov. } 17 .
$$

' Hubinont, P. O., Nature, 162, 457 (1948).

' Race, R. R. (personal communication).

Andresen, P. H., Acta Path. (in the press).

\section{'Brassy' Eosinophilic Granulocytes and their Possible Role in Iron Transport}

Is blood films stained by one of the Romanowsky modifications, the granules of the eosinophiles are ordinarily scarlet. Occasionally, however, they exhibit a range of colour modification which varies from brownish-red, through grey to almost coal-black. The latter granules are not to be confused with those of the basophilic granulocyte, which have also been found in otherwise unaltered 'eosinophiles' in autochthonous hyperheparinæmias ; truly basophilic granules are metachromatic when stained with toluidine blue, while the dark granules of the 'brassy' eosinophiles (as such cells have come to be termed in laboratory parlance) are not basophilic nor do they stain with toluidine blue. The appearance of the 'brassy' granule does not seem to be a staining artefact, as they appear preponderantly in the blood films of certain individuals even though these blood films have been subjected to identical and concurrent staining procedure with films exhibiting the scarlet eosinophilic granule.

The probable nature of the 'brassy' granule was disclosed inadvertently in another connexion. A patient with megaloblastic anæmia was given parenteral liver extract therapy and made a good response with the usual reticulocytosis, increase in blood cholinesterase and eosinophilia, but the anæmia shifted to a hypochromic type. The latter phase was then treated with ferrous lactobionate solution given intravenously. On one occasion, when it was desired to make a routine blood study (to save the patient an additional venipuncture), blood was aspirated directly into the syringe from which the iron solution had just been expressed. The smear from this blood showed all eosinophiles to be of the 'brassy' type. The addition of small quantities of ferrous salts to blood samples was found to convert the ordinary eosinophilic granule to the 'brassy' form. That this form may represent an iron conjugate of the eosinophilic granule is a possibility that might open the additional possibility that the eosinophile is concerned in some phase of iron transport.

ROBERT D. BARNARD

138-48 231st Street,

Laurelton, Long Island,

New York City.

Aug. 14.

\section{Amino-Acid Constitution of Diphtheria Toxin and Toxoid}

WHILE examining by two-dimensional paper partition chromatography the acid hydrolysates of highly purified diphtheria toxin and toxoid, preparatory to attempting the quantitative estimation of the constituent amino-acids by the method of Woiwod ${ }^{1,2}$, a striking qualitative difference has been observed between the chromatograms of these two substances, which we feel may be significant.

The photograph of a typical chromatogram of the hydrolysate of toxin is given in Fig. 1, while that of toxoid is shown in Fig. 2. It will be seen that tyrosine is present in the toxin but not in the toxoid hydrolysate. No other major differences have been observed between the chromatograms.

The highly purified diphtheria toxin and toxoid used in this work were prepared by the method of Pope and Linggood (unpublished), and both prepara. tions contained 2,100-2,200 Lfs./mgm. protein nitro- 